\title{
TEORIAS DA CONSPIRAÇÃO NO MOVIMENTO NOVA ERA
}

\author{
Conspiracy theories in the New Age Movement
}

Silas Guerriero. ${ }^{1}$

Carlos Bein ${ }^{2}$

\begin{abstract}
RESUMO
As Teorias da Conspiração apresentam um viés semelhante às estruturas religiosas. Ao mesmo tempo, algumas religiões podem conter componentes conspiratórios em seus conjuntos de crenças. O objetivo do trabalho é perceber como essas características paralelas acabaram gerando configurações bastante específicas à forma de religiosidade difusa do ethos nova era. Teorias da conspiração estiveram presentes no Movimento Nova Era desde seus primórdios e, em muitos casos, continuam influenciando seus adeptos até os dias atuais. Alcunhada nas primeiras décadas de Conspiração Aquariana, o movimento Nova Era procurava incrementar uma profunda transformação nos rumos da humanidade, libertando-a das limitações materialistas e almejando a plena realização espiritual. De modo mais específico, o trabalho analisa aspectos do gnosticismo, um dos elementos constituintes originários da Nova Era, como inspirador de muitas de suas teorias da conspiração, notadamente as ideias do acesso a uma sabedoria oculta, a luta pela libertação da humanidade e a derrota do mal pelo bem. A pesquisa utilizou materiais bibliográficos e fontes históricas de diferentes grupos da Nova Era, bem como análises sobre aspectos do comportamento contemporâneo que são influenciados pelo ethos nova era. Pode-se concluir que a Nova Era não apenas foi alimentada por teorias da conspiração, como alimentou, e continua alimentando, outras mais até a presente data.
\end{abstract}

Palavras-chave: Nova Era; Teorias da Conspiração; Gnosticismo; Bem e Mal.

\begin{abstract}
Conspiracy Theories have a similar bias to religious structures. At the same time, some religions may contain conspiratorial components in their belief sets. The aim of the paper is to see how these parallel characteristics ended up generating configurations quite specific to the diffuse form of religiosity of the New Age ethos. Conspiracy theories have been present in the New Age Movement since its beginnings and, in many cases, continue to influence its adherents to this day. Nicknamed in the first decades as the Aquarian Conspiracy, the New Age Movement use to sought to increase a profound transformation of humanity, freeing it from materialistic limitations, aiming at full spiritual realization. More specifically, the paper analyzes aspects of Gnosticism, one of the original constituent elements of New Age, as the inspiration for many of its conspiracy theories, notably the ideas of access to a hidden wisdom, the struggle for the liberation of mankind and the defeat of evil by good. The research used bibliographic materials and historical sources from different New Age groups, as well as analysis on aspects of contemporary behavior that are influenced by the New Age ethos. It can be concluded that the New Age was not only fueled by conspiracy theories, but was also fueled by them, and continues to fuel them to the present day.
\end{abstract}

Keywords: New Age; Conspiracy Theories; Gnosticism; Good and Evil.

\footnotetext{
1 Doutor em Antropologia, professor do Programa de Pós-Graduação em Ciência da Religião da PUC-SP e coordenador do NEO - Núcleo de Estudos de Novas Religiões e Novas Espiritualidades (PUC-SP).

2 Mestre em Ciência da Religião pela PUC-SP e pesquisador do NEO -: Núcleo de Estudos de Novas Religiões e Novas Espiritualidades (PUC-SP). Tem experiência nas áreas de psicologia analítica e esoterismo. REVISTA RELEGENS THRÉSKEIA - 2021 - UFPR
} 


\section{Introdução}

A participação de manifestantes de extrema direita ligados ao grupo QAnon portando símbolos neopagãos, chamou a atenção de muitos nas manifestações pró Trump nas últimas eleições estadunidenses. O QAnon defende a ideia de que há uma grande conspiração, ligada a adoradores do diabo, que estaria jogando contra o ex-presidente Donald Trump e seus apoiadores. O neopaganismo sempre teve forte ligação com o movimento Nova Era, sendo uma de suas vertentes formais mais visíveis. O fato estranho é de que a Nova Era está, ao menos simbolicamente, ligada ao movimento de paz e amor da contracultura dos anos 1960.

Como compreender, portanto, essa presença de teorias conspiratórias aparentemente contraditórias no interior de um mesmo movimento?

Um olhar mais aprofundado sobre os grupos neopagãos mostra que só poucos entre eles são propriamente novaeristas. Existe uma tradição do neopaganismo associado a outras ideologias, com pouco ou nada a ver com a Nova Era. Hanegraaff aponta que o termo neopagão engloba duas tendências, uma delas politicamente discutível e a outra ligada ao fenômeno Nova Era, sem nada a ver com o radicalismo da primeira. O neopaganismo novaerista deve, portanto, distinguir-se das tentativas de revitalizar a visão de mundo de culturas europeias pré-cristãs (HANEGRAAFF, 1996, p.77).

De certa maneia, tal explicação colocaria as coisas em seus devidos lugares, e a Nova Era poderia navegar tranquila, mais uma vez, num mar de águas tranquilas e pacíficas, voltada à elevação espiritual na melhor das ações intencionadas. No entanto, constata-se efetivamente que também na Nova Era aparecem teorias da conspiração, não somente em grupos novaeristas neopagãos. Ou seja, embora envolta em um discurso alternativo e unificador, a Nova Era apresenta, também, seu lado político e conspiratório.

Este artigo se propõe a discutir as teorias da conspiração relacionadas à Nova Era. As Teorias da Conspiração apresentam um viés semelhante às estruturas religiosas. Ao mesmo tempo, algumas religiões podem conter componentes conspiratórios em seus conjuntos de crenças. De certa maneira, o Movimento Nova Era foi alimentado, desde seus primórdios, por teorias da conspiração. O objetivo é perceber como essas características paralelas acabaram gerando configurações bastante específicas à forma de religiosidade difusa do ethos nova era. O presente trabalho procura analisar as teorias da conspiração presentes no movimento Nova Era, através de alguns de seus exemplos mais marcantes. Em primeiro lugar, voltaremos nossos 
olhares para a denominada Conspiração Aquariana, uma espécie de contraconspiração voltada para o que seus adeptos entenderiam como sendo "do bem". Em seguida analisaremos brevemente como as teorias da conspiração guardam profundas semelhanças com o pensamento religioso e como estas estão presentes na Nova Era. Apresentaremos algumas das teorias da conspiração que marcaram o início desse movimento Nova Era. Dentre esses, tomaremos o caso específico do gnosticismo. Algumas reações à conspiração aquariana, vindas de setores reacionários, serão apresentadas na sequência. Por fim, avançaremos na análise da Nova Era a partir desse campo das teorias da conspiração.

\section{A conspiração aquariana}

O movimento Nova Era apresenta uma aparência de liberalidade religiosa e alto grau de relativismo e tolerância (GUERRIERO, 2005; 2017). No entanto, é possível perceber que desde seus primórdios, a Nova Era esteve envolta em teorias conspiratórias. Essas teorias apresentam um forte viés religioso (FRANKS; BANGERTER; BAUER, 2013), e isso não poderia ser diferente em relação àquelas que estiveram, ou estão, ligadas direta ou indiretamente ao movimento Nova Era. A duplicidade entre a dinâmica religiosa das teorias da conspiração e as teorias que alimentam a Nova Era acabou gerando características evidentes da forma de religiosidade difusa desse novo ethos (GUERRIERO et al., 2016).

Se tivermos que eleger um aspecto central do movimento Nova Era, um verdadeiro "mito fundador", apontaríamos a questão básica da existência de um conhecimento fundamental que envolve o potencial da mente humana e que tem sido escamoteado por séculos impedindo que a humanidade se desenvolva plenamente. A denominada Era de Aquário, a então verdadeira era nova, seria o despertar desse conhecimento oculto e a consequente construção de um era de esplendor e elevação espiritual.

O Movimento do Potencial Humano, surgido nos idos da contracultura dos anos 1960 através de pensadores ligados ao Instituto Esalen, na California, com viés psicológico, mas com fortes influências esotéricas, pregava que as mentes mais brilhantes do planeta não usariam mais que $10 \%$ de suas capacidades mentais. Através do resgate de uma sabedoria milenar e do desprendimento das amarras que as grandes instituições sociais impunham, como a Igreja Católica, os governos das grandes potências e até mesmo a ciência, um indivíduo poderia atingir a plenitude do potencial de suas mentes, cultivar a felicidade e construir uma nova era para a humanidade. A sugestão básica é a de que todos nós poderíamos alcançar essa plena felicidade, 
uma verdadeira salvação. O problema é que haveria uma grande conspiração, do mal, que acabava impedindo esse feito.

O movimento Nova Era fora mais conhecido, naquele período inicial, pela sua referência astrológica. A então esperada Era de Aquário substituiria a Era de Peixes. As eras astrológicas, de aproximadamente dois mil anos cada, estariam relacionadas à inclinação do eixo terrestre em relação aos signos zodiacais. Os astrólogos acreditam que o signo correspondente, dominante de uma era inteira, teria o poder de influenciar não apenas os indivíduos, mas a história como um todo. A Era de Peixes, período de dois mil anos de dominação do cristianismo, seria fortemente patriarcal, com um modelo hierárquico centralizado e dominado pelas grandes instituições. A visão dualista seria a imperiosa nesse período, pois colocava o ser humano como distinto da divindade. Outro aspecto fortemente dual, seria o das forças do bem e do mal como entidades ontológicas distintas.

A nova era, ou a Era de Aquário, período em que a humanidade estaria começando a vivenciar, traria uma visão monista (CAMPBELL, 1997), denominada de holística pelos seus praticantes, em que o divino poderia ser encontrado no interior do self e o mal estaria vinculado ao aspecto da incapacidade do ser humano de atingir seu pleno conhecimento e espiritualidade.

Marilyn Ferguson foi uma escritora e jornalista que viveu intensamente aqueles primeiros momentos do movimento Nova Era. Na década de 1970 resolveu colocar na forma de livro o que seria, para ela e para aqueles à sua volta, uma verdadeira conspiração voltada para o bem. Na medida em que se situava na lógica dualista de bandos que se enfrentavam, entre uma cultura repressora e uma contracultura libertadora, não teve dificuldade em expressar o conflito em termos de conspiração. Só que, segundo ela, os conspiradores seriam os próprios novaeristas. Ferguson utilizou a expressão Conspiração Aquariana (Aquarian Conspiracy) para intitular sua obra, publicada originalmente em 1980 (FERGUSON, 1995). Hanegraaff considera esse livro como um primeiro manifesto da Nova Era sensu lato. Esse autor costuma separar a Nova Era em dois momentos distintos, embora muitas vezes sobrepostos, a Nova Era sensu stricto, ou seja, os primeiros anos da Nova Era, seu sentido estrito, compostas por grupos mais exclusivistas, e Nova Era sensu lato, mais aberta à sociedade, ou seja, uma Nova Era num sentido amplo (HANEGRAAFF, 1996, pp. 98-103).

Para esse autor, a Nova Era tem origens bastante antigas, sendo um reflexo da secularização do esoterismo ocidental em curso desde o século XIX e do desenvolvimento de correntes psicológicas como a Psicologia Analítica de Carl Jung e posteriormente o Movimento do Potencial Humano. Em seus primeiros anos, a ênfase recaia na formação de grupos fechados, que rejeitavam o mundo circundante e propunham uma nova sociedade alternativa. Isso significava romper valores e cultivar novos hábitos. 
Vários grupos foram formados, alguns deles com características bastante sectárias e alimentados por teorias conspiratórias. A tônica era a de se preparar para uma nova fase do planeta, uma nova era. Esse período, que durou até meados dos anos 1980, foi o da Nova Era sensu stricto. Sem significar o desaparecimento desses movimentos que pregavam uma rejeição do que estava instituído, e que existem até os dias atuais, a denominada Nova Era sensu lato começou a predominar nas últimas décadas do século XX. Esse novo momento significou algo muito mais profundo e amplo, refletindo características culturais dos nossos tempos que vão além da formação de um grupo sectário. Tal formação pode ser percebida em todos os lugares onde a Nova Era se manifestou, inclusive no Brasil. Temos percebido esse momento como aquele que encontra um verdadeiro ethos nova era permeando as relações sociais. (GUERRIERO et al., 2016)

Teríamos, então, o cultic milieu, descrito por CAMPBELL (1972) tomando consciência de si mesmo. Assim, a conspiração aquariana consistiria em redes não hierarquizadas de pessoas com mentalidades similares que mudariam os fundamentos da moderna sociedade industrializada (HANEGRAAFF, 1996, p. 98).

Ferguson explica como, ainda no começo dos anos 1970, quando preparava um livro sobre o cérebro e a consciência, ela se deparou com descobertas científicas que supostamente demonstrariam capacidades humanas que iam muito além daquilo que se considerava "a norma". Ao mesmo tempo, observou que muitas outras pessoas estavam também descobrindo novos fenômenos mentais, tais como aprendizado acelerado, conscientização expandida, o poder do imaginário interior para a cura e a resolução de problemas e a possibilidade de recobrar memórias ocultas.

Tais descobertas comporiam, segundo ela, uma verdadeira revolução da consciência, que formaria uma síntese com o ativismo social dos anos 1960: uma transformação social resultante das mudanças interiores que estariam acontecendo nos indivíduos. Essa nova sociedade, em termos centrais, se caracterizaria por organizações fluídas, não hierarquizadas, contrárias a dogmas, integrando o antigo e o novo, magia e ciência, arte e tecnologia.

A questão, para Ferguson, seria que essa nova forma de se organizar iria além da simples cooperação. Tratar-se-ia de um conluio, de uma conspiração, e daí o título do livro.

Ferguson se preocupou em afirmar que não utiliza o termo "conspirar" no seu significado habitual em inglês, idioma original de seu livro, com suas associações negativas, como tramar por algo futuro agindo por atos ilícitos (unlawful) ou indevidos (wrongful). Ferguson diz utilizar "conspiração" no que seria, segundo ela, seu significado literal, "corespirar" ou respirar junto, bem no espírito da Nova Era. 
A fim de tornar clara a natureza benévola dessa ligação escolhi a palavra "Aquariana". Embora me faltem conhecimentos astrológicos, fui atraída pela força simbólica do sonho difundido em nossa cultura popular: que após uma era violenta e negra, a de Peixes, estamos entrando em um milênio de luz e de amor, ou, como diz uma canção popular, "a Era de Aquário", a era da "verdadeira libertação da mente". (FERGUSON, 1995, p. 19)

O símbolo de Aquário, expressando, segundo Ferguson, fluxo e satisfação de antigos desejos, resultava apropriado para a nova época que estava chegando, independentemente de que isso estivesse escrito ou não nas estrelas. Estaria assim expressando a solidariedade e harmonia do movimento.

No começo, os "conspiradores" não pensariam em mudar a sociedade e, portanto, não teria sentido o termo conspiração. No entanto, aos poucos teria lugar uma mudança pessoal, de modo que eles perceberiam suas vidas como sofrendo uma revolução, repensando tudo, examinando velhas suposições, enxergando de um modo novo seu trabalho e relacionamentos, saúde, poder político, objetivos e valores.

Os conspiradores aquarianos se situariam em todos os níveis sociais, econômicos e educativos, desde os mais humildes aos mais elevados. No entanto, todos eles estariam unidos por suas descobertas e grandes mudanças internas. No começo de suas descobertas no nível individual, muitas pessoas não teriam pensado em mudar a sociedade. Mas, ao longo de seu percurso de transformação, elas perceberiam suas vidas como revoluções, de modo que repensariam e reavaliariam velhas suposições, olhando de um modo inovador o trabalho, os relacionamentos, a saúde, a política, seus objetivos e valores.

Não se trataria de um novo sistema político, religioso ou filosófico. Mais do que isso, seria uma nova mentalidade. Nada a ver com afiliações tradicionais, nada de partidos políticos, grupos ideológicos, clubes ou organizações fraternais. Em lugar disso, seriam pequenos agrupamentos e redes informais. Existiriam dezenas de milhares de pontos de entrada nessa conspiração. Onde quer que as pessoas compartilhassem suas experiências, elas se conectariam cedo ou tarde umas com as outras e, posteriormente, em círculos maiores. Tratava-se, segundo Ferguson, de uma conspiração sem líderes, da qual participavam pessoas de todos os níveis econômicos e educativos, desde o mais humilde ao mais elevado.

A conspiração abarcaria muitos outros aspectos da atividade humana. Grandes inovações da ciência convergiriam para essa mudança de paradigma. Se a sociedade estava transitando a novas formas de relacionamento, a física quântica estaria demonstrando a unidade de objetos aparentemente separados, confirmando com isso a visão imemorial dos místicos. A nova física mostraria paralelismos com antigas descrições místicas da realidade (FERGUSON, 
p. 162). Junto a isso, fenômenos psíquicos como clarividência, telepatia, precognição, psicocinesia e sincronicidade resultariam tanto ou mais surpreendentes. Esses fenômenos estariam sendo testados cientificamente mostrando um elevado grau de evidência. A intenção humana se demonstraria capaz de interagir a distância com a matéria. Contudo, o modo em que a mente e o mundo físico interagem ainda seria um mistério (FERGUSON, p. 165). Ferguson compara o novo movimento com o situar de uma nova estrela num planisfério: ao nomeá-la se faz visível, mas na verdade sempre teria estado presente. Não é simples coincidência que o livro do então físico, e depois verdadeiro guru da Nova Era, Fritjof Capra, O Tao da Física, publicado originalmente em 1975, tenha sido bastante citado no livro de Ferguson.

Há um outro lado importante para ser acrescentado sobre o movimento Nova Era. Hanegraff (1996, p.409) identificou o movimento Nova Era como uma "religião secularizada". Por mais do que seus agentes tenham identificado como uma novidade, seus fundamentos se encontram no ocultismo, num esoterismo completamente secularizado. Tal identificação se fazia visível, segundo Hanegraaff, em dois sentidos. Primeiramente pela mistura de correspondências com o próprio pensamento científico, como a noção de causalidade. Em segundo lugar, apresentaria uma visão altamente evolucionista.

As raízes gnósticas do esoterismo ocidental acabaram influenciando o universo da Nova Era. Goodrick-Clarke (2002, pp. 300-301) entende que as teorias conspiratórias podem ser rastreadas até as ideias antigas do gnosticismo, nas quais a humanidade estaria escravizada por um deus maligno, criador da matéria e do reino inferior. Somente um deus mais alto possibilitaria uma redenção espiritual. A característica religiosa das teorias da conspiração, que será trabalhada mais a frente, pode ser também aplicada à tradição gnóstica, deixando traços marcados em diversos movimentos religiosos.

Gnose em grego significa conhecimento, mas no contexto do gnosticismo se trata de um conhecimento espiritual, que se contraporia à fé e à razão. Hanegraaff desenvolve a ideia de Gilles Quispel, segundo a qual razão, fé e gnose seriam três componentes básicas na tradição cultural europeia. A razão teria seu início na antiga filosofia grega e culminaria na ciência moderna. A fé seria o principal componente no pensamento cristão, baseado na revelação divina mediada pelas Sagradas Escrituras e/ou pela tradição. Por fim, na gnose, a experiência de divino ou do self prevaleceria sobre a simples razão ou fé (HANEGRAAFF, 1998, pp. 372-373). O componente gnóstico pode ser considerado como a "contracultura tradicional do ocidente" (HANEGRAAFF, 1998, p. 373), muito problemática e com frequência inaceitável desde as outras duas perspectivas. Como resultado, tem sido associada a ela qualquer ideia considerada 
incompatível com as tendências dominantes. Pessoas que percebem alguma coisa de errado no seu entorno cultural, aproximam-se dessa tradição. Hanegraaff vê uma "forte ênfase do movimento Nova Era na experiência pessoal interior, do 'self' como autoridade última da verdade e como o único meio de entender a verdadeira própria relação com o universo e Deus”. Conclui que "Neste sentido, o movimento da Nova Era está evidentemente baseado na 'gnose"” (HANEGRAAFF, 1998, p. 373, tradução nossa). Além disso, o gnosticismo teria para os novaeristas o atrativo das "implicações românticas de uma religião 'pacífica e mística' suprimida cruelmente por uma igreja estadual 'violenta e dogmática"' (HANEGRAAFF, 1998, p. 373 , tradução nossa).

\section{As teorias da conspiração, o pensamento religioso e a Nova Era}

As teorias da conspiração podem assumir muitas formas e variam amplamente em popularidade na intensidade com que são acreditadas e em seus efeitos no comportamento individual e coletivo. Segundo Franks, Bangerter e Bauer, embora as tendências recentes na política e na mídia façam parecer que as teorias da conspiração estão em ascensão, na verdade elas sempre estiveram presentes, provavelmente devido a estar sustentadas por disposições naturais da mente humana (FRANKS; BANGERTER; BAUER, 2013, p. 424). Uma de suas principais características é que fornecem explicações causais para eventos sociais complexos. A ideia conspiradora está enraizada em uma tendencia geral de explicar e racionalizar fenômenos complexos do mundo real em um conjunto coerente de pressupostos sobre a existência de um inimigo poderoso e malvado, destacando a necessidade das pessoas de explicar eventos que são difíceis de compreender (FRANKS; BANGERTER; BAUER, 2013, p. 427).

O mecanismo cognitivo das teorias da conspiração leva a uma visão de mundo geral capaz de explicar eventos que são tidos como ameaçadores ou desconhecidos. Resulta em um subconjunto de narrativas que se acredita que a causa final de um evento seja devido a uma trama malévola de vários atores trabalhando juntos (FRANKS; BANGERTER; BAUER, 2013, p. 425).

Segundo esses autores, as teorias da conspiração podem ser vistas como quase-religiões, ou seja, embora não sejam necessariamente relacionadas a grupos religiosos (muitas vezes o são) as teorias da conspiração envolvem os mesmos mecanismos cognitivos e de representações que vemos atuando nas religiões. Assim como em uma religião há a percepção de agentes responsáveis pelos acontecimentos, nas teorias da conspiração há sempre a ideia de que algum agente, indivíduo, grupo de indivíduos ou instituição, é responsável por uma situação real de 
conflito ou de um confronto em potencial. São, também, narrativas que circulam na cultura. Essas narrativas reduzem a complexidade apresentada por tais eventos, diminuem a incerteza que eles geram e traduzem a ansiedade em medos focalizados (FRANKS; BANGERTER; BAUER, 2013, p. 429).

Esse mecanismo de crença encontra padronicidades na realidade ao redor, bem como insiste na imputação da responsabilidade da ação a agentes externos. Além disso, é forte sua capacidade de reprodução por contarem com elementos significativamente atrativos. Todas essas características fazem com que as teorias da conspiração se perpetuem e se atualizem constantemente. Não poderia deixar de estar, portanto, também presentes na Nova Era.

David Spangler, filósofo espiritualista estadunidense, foi um dos grandes mentores das primeiras fases da Nova Era (Nova Era sensu stricto), sendo um dos líderes da comunidade rural Findhorn, na Escócia. Segundo Hamegraaff (1996, p. 38), Spangler pode ser considerado como o "teólogo residente" de Findhorn. A partir do que ele entendeu como uma "chamada interior", Spangler deixou os EUA ainda jovem rumo à Europa em 1970, pois a voz interior lhe havia dito que lá ele encontraria as chaves para um próximo ciclo espiritual. David Spangler é considerado, muitas vezes, o pai do movimento Nova Era (HANEGRAAFF, p. 104). Findhorn foi fundada em 1962, bem no início do movimento, pelo casal Peter e Eileen Caddy e sua amiga Dorothy Maclean. O desejo era o de seguir um caminho espiritual disciplinado a partir de vozes interiores que os levaram a formar a comunidade. Já com relativo sucesso, Spangler se juntou ao grupo, de então 300 pessoas aproximadamente, em 1970, implementando um verdadeiro currículo espiritual de aprendizagem. A comunidade de Findhorn é considerada o mais famoso exemplo de comunidades alternativas, que floresceram fortemente a partir do movimento de contracultura dos anos 1960 (HANEGRAAFF, 1996, p. 96).

Spangler afirmava que a humanidade estaria presa a um materialismo atroz e fortemente resistente a mudanças. Essa velha civilização estaria dominada por poucas corporações, entre elas as igrejas monoteístas e um conglomerado de governos, com o firme propósito de se perpetuarem no poder. Para ele, a transição para a um novo momento aquariano se daria pela destruição dessa velha civilização, destruição essa que seria causada por ela mesma, devido a desastres ambientais, ou até mesmo por uma guerra nuclear. Numa visão bastante milenarista, os indivíduos que tivessem atingido a consciência planetária seriam protegidos e sobreviveriam. Importante dizer que tudo isso se daria através da ajuda de extraterrestres. Posteriormente, com as mudanças para uma Nova Era sensu lato, em que a luta entre o bem e o mal não se configurariam tão nitidamente, David Spangler passou a ser um grande crítico dos rumos 
comerciais e consumistas que esse movimento acabou tendo. Em 2010, publicou suas memórias, com o título que pode ser traduzido como "Aprendizados do Espírito", em que relata sua trajetória espiritual, desde Findhorm até a fase mais recente, em busca do desenvolvimento de uma espiritualidade encarnada (SPANGLER, 2010).

Uma das fontes impulsionadoras do movimento Nova Era dos anos 1960 foram os supostos avistamentos de objetos voadores não identificados e os contatos estabelecidos com seres alienígenas, principalmente nos anos 1950. Um desses personagens mais difundidos foi, sem dúvida, Ashtar Sheran. Bem no espírito da Nova Era, esse ser extraterrestre foi identificado como um avatar de diferentes religiões, de anjo a caboclo das sete encruzilhas, ou mesmo um intermediário de Jesus Cristo, o grande governante espiritual do planeta Terra. Suas primeiras canalizações se deram em 1952 através de um norte americano, George Van Tassel, muito preocupado com a ameaça nuclear (DURÁN; LOPEZ MOYA, 2011, p. 66). Rapidamente essas supostas mensagens começaram a se difundir e várias outras pessoas começaram a recebê-las, inclusive no Brasil (VERONESI, 2021, p.4). Ashtar Sheran é considerado um vigilante da evolução de raças superiores e inteligentes da Via Láctea, descendente do arcanjo Miguel. Importante notar que sua imagem é sempre retratada como um loiro de olhos azuis, bem ao estilo europeizado da imagem de Jesus. Sheran teria entrado em contato com algumas pessoas selecionadas daqui da Terra, devido a seu grau de elevação espiritual, para passar a mensagem sobre os riscos que a humanidade estaria enfrentando. Trazendo um conhecimento superior, esses seres ajudariam a impedir uma guerra nuclear, bem como trariam a sabedoria para nos auxiliar rumo à elevação espiritual. Há um forte apelo para resistir a uma conspiração dos meios de comunicação que defenderiam a necessidade de uma corrida armamentista. Sheran afirmaria ser isso uma mentiria e que a humanidade precisaria caminhar rumo à elaboração de uma paz mundial (DURÁN; LOPEZ MOYA, 2011, p. 67).

Significativo, também, é o movimento raeliano, criado por um francês nos anos 1970, que teria tido contato com extraterrestres. Claude Vourilhon, autodenominado profeta Raël, atribuiu a criação da vida humana na Terra a seres de outros planetas. Estes estariam transmitindo a informação aos humanos de que um novo momento estaria próximo. Para nos salvar das desgraças do mundo, grandes líderes espirituais, como Moises, Jesus, Maomé, entre eles, retornariam, desde que nós, por aqui, nos tornássemos conscientes e pacíficos. Essa nova ordem, formada por esses humanos conscientes com a ajuda desses seres extraterrestres, substituiria a situação de desgraça pela qual o planeta estaria passando. Esse grupo existe até 
os nossos dias e, por vezes, se quer fazer presente no âmbito político, como por exemplo criar uma embaixada dos extraterrestres aqui no Planeta Terra (LISBOA, 2021).

No presente momento, preocupados com os rumos que os humanos estariam dando ao planeta, esses extraterrestres estariam enviando mensagens, através do profeta Raël, que nos libertariam das "amarras obscurantistas das sociedades menos evoluídas" (MACHADO, 2006, p. 12). O discurso conspiracionista estaria relacionado aos interesses das grandes empresas e dos meios de comunicação que estariam fazendo um uso equivocado da ciência. Um dos pontos altos, e de maior repercussão, foi quando o movimento anunciou, em 2002 e com grande estardalhaço, o nascimento de um primeiro clone humano, denominado Eva pelas lideranças do grupo (MACHADO, 2006, p. 23).

Mais famosos e carismáticos são os Iluminatti. Há uma grande aura de ficção, imaginação e até realidade que envolve esses integrantes de uma sociedade secreta que seriam os controladores por detrás de grandes eventos. Esse grupo, ao contrário dos anteriores, não estaria ao lado do bem, ou da elevação espiritual de muitos, mas com forte intuito de controlar o planeta em detrimento da grande maioria da humanidade. No entanto, a fonte alimentadora dessa teoria da conspiração é o próprio cultic milieu da Nova Era. Há um conhecimento secreto a ser alcançado por poucos através do necessário desses que teriam consciência espiritual já elevada.

Em Black Sun, livro publicado em 2002, Nicholas Goodrick-Clarke, filósofo e estudioso do esoterismo e suas ligações com o nazismo, esclarece que os Illuminati seriam uma sociedade secreta fundada na Bavaria em 1776 pelo jesuíta Adam Weishaupt (1748-1830). O fundador tinha uma visão igualitária, racional e anticlerical. Esta ordem dos Illuminati foi banida pelas autoridades da Bavaria em 1786. A partir do final dos anos 1960, os Illuminati passaram a formar parte das ideias da direita radical norte-americana (GOODRICK-CLARKE, 2002, p.286). Desde então, essa ordem tem sido um dos temas principais da literatura estadunidense sobre conspirações. Segundo esse autor, o crescimento da fama dos Illuninati se deu principalmente a partir dos anos 1990 através de um antigo militar da marinha dos Estados Unidos, Milton William Cooper, com forte influência da Nova Era, que afirmava ser os judeus os grandes conspiradores responsáveis pela criação de discórdias e hostilidades com outros países, visando provocar guerras contra seus oponentes. A cizânia criada pelos Illuminati visava a desorientação e distração da população com o intuito de estabelecer uma Nova Ordem Mundial. Esse Willian Cooper estava até mesmo convencido de que a Inteligência Naval, orientada pelos Illuminati, havia participado do assassinato de John F. Kennedy. (GOODRICK- 
CLARKE, 2002, p.289). Uma das provas dessa influência sobre o estado norte-americano seria a utilização de símbolos cabalísticos e ocultistas, como a pirâmide e o grande olho que tudo vê, em documentos oficiais e nas notas de um dólar.

Outras teorias da conspiração fazem parte, também, da Nova Era. Goodrick-Clarke expõe como, após a queda da União Soviética e nos anos finais do século XX, houve um chamado para uma "Nova Ordem Mundial" por políticos tanto dos Estados Unidos como da Rússia (GOODRICK-CLARKE, 2002, p. 279). Os governos de diferentes países sofreram um aumento de regulação por organismos supranacionais. Nos Estados Unidos isso causou para muitos um medo nacionalista ao que era interpretado como socialismo e autoritarismo burocrático. Na Europa, o aumento da integração federal da então União Europeia produziu medos semelhantes a respeito da regulação administrativa e perda de soberania nacional dos estados. Fomentou-se com isso a formação de mitos conspiracionistas em determinados grupos sociais.

As teorias da conspiração tinham já uma longa presença na direita radical europeia e norte-americana. No entanto, Goodrick-Clarke qualifica de fenômeno preocupante a difusão de teorias conspirativas no milieu Nova Era. Um interesse anarco-libertário em rastejar experimentos de controle mental da CIA, operações encobertas do governo federal e conexões com discos voadores e alienígenas pode mudar subitamente, afirmava Goodrick-Clarke, para um discurso pessimista de elites hostis e ameaças ocultas. Alguns novaeristas poderiam se sentir decepcionados por uma sociedade que fracassou em transformar-se espiritualmente como se aspirava nas décadas de 1970 e 1980. O fato é que a tão almejada Nova Era não chegou, gerando fortes desapontamentos e insatisfações. Nesse sentido, Hanegraaff chama a atenção sobre a alteração do subtítulo do livro de Marilyn Ferguson em edições posteriores, que mudou de “Transformações Pessoais e Sociais nos anos 80" para "Transformações Pessoais e Sociais no Nosso Tempo"3 (HANEGRAAFF, 1996, p. 107).

Assim, enquanto em 1980 Ferguson falava em conspiração aquariana para a chegada da Era de Aquário, nos anos de 1990-2000 os conspiradores passaram a ser aqueles que se opunham e agiam em oposição à esperada Nova Era. Essa nova conspiração se explicava por novas teorias conspiratórias, aponta Goodrick-Clarke.

\footnotetext{
${ }^{3}$ Em sucessivas traduções ao português encontradas na Internet, o subtítulo "personal and social transformation in our time" aparece como "Transformações humanas e sociais no final do século XX", sendo que na primeira edição era, efetivamente, "transformações pessoais e sociais nos anos 80", mais de acordo com o original inglês "Personal and Social Transformation in the 1980s".
} 
Reparações espirituais mediante velas, tarô, runas e oficinas druídicas para tranquilizar o mundo interior podem se misturar facilmente com fantasias em oposição àquilo que está estragando as coisas (GOODRICK-CLARKE, p. 299). No entanto, Goodrick-Clarke alerta que, mesmo as ideias da Nova Era tendo suas raízes na dissidência da esquerda, a tendência crescente a teorias da conspiração e desesperança denota uma predisposição a ideias milenaristas e místicas da extrema direita. Muitas pessoas, desanimadas pelo avanço da tecnologia e a economia global, se retiraram a subculturas onde complôs fantásticos e ameaçadores de qualquer tipo parecem possíveis (GOODRICK-CLARKE, p. 300).

Para Goodrick-Clarke o conspiracionismo anti Nova Era seria resultado da crise dos anos 1990-2000, cabendo perguntar se as teorias da conspiração não estariam implícitas na Nova Era desde o começo, ou mesmo até que ponto o pensamento conspiratório formaria parte de qualquer religião. Tal questionamento pode ser respondido pelo que vimos anteriormente, tanto em termos das características religiosas das teorias da conspiração, como da inclinação da Nova Era para com estas, a começar da maquinação visionária de Marilyn Ferguson.

Um último recente exemplo de teorias da conspiração na linha apontada por GoodrickClarke é trazido por Emilio Carrillo ${ }^{4}$ em seu livro Conciencia y sociedad distópica (CARRILlO, 2020). Os valores de Carrillo se encaixam com os da Nova Era. Muitas características do seu livro fazem pensar em A Conspiração Aquariana, de Marilyn Ferguson. Segundo Carrillo, o mundo estaria caminhando de um modo espontâneo para a Nova Era, mas uma elite estaria conspirando para impedi-lo. Muitas das características da conspiração descrita por Carrillo podem ser encontras nos autores citados por Goodrick-Clarke, não necessariamente autores novaeristas.

Carrillo fala de uma elite nas sombras, detentora do poder, que controlaria o mundo através de uma série de círculos concêntricos de elites e sub-elites, dominadora da economia e da sociedade em escala global, chegando a controlar a vida dos indivíduos, sem que eles sejam conscientes (CARRILLO, 2020, p. 209).

Segundo Carrillo, o primeiro círculo não está constituído por seres humanos, mas por seres sutis, sem corporeidade material, mesmo que eles possam se manifestar visivelmente. Eles possuem meios de atuação impensáveis para a humanidade. Mesmo tratando-se de seres sutis, eles possuem uma alta densidade de consciência. Eles estão apegados a insaciáveis desejos egóicos de poder. Diversos textos antigos fazem referência a eles, como em Mateus 4:10, na figura de Satanás, o príncipe deste mundo em João 12:31 e o "deus deste século" na Segunda

\footnotetext{
${ }^{4}$ Escritor espanhol contemporâneo que trata de assuntos relacionados a espiritualidade e consciência.
} REVISTARELEGENS THRÉSKEIA - 2021 - UFPR 
Carta aos Coríntios 4:4, de Paulo. Eles estão relacionados com outros seres "de baixa frequência consciencial" mas tecnologicamente avançadas e conhecedoras das forças naturais (CARRILLO, 2020, p. 209). Entre esses seres há diversas raças extraterrestres, assim como entidades “plúmbeas e sombrias” (CARRILLO, 2020, p. 209).

O segundo círculo, continua Carrillo, está formado pelos já mencionados Illuminati. Esse pequeno círculo de pessoas que ao longo dos séculos prestariam deliberadamente serviço a Satanás em troca de poder e riqueza. Controlam a economia e a sociedade em escala planetária. O primeiro círculo deixa ao seu dispor conhecimentos e tecnologia extraterrestre mediante os quais dominam a humanidade. Utilizam leis, religiões e normas morais para adestrar e alienar os humanos. O terceiro círculo está formado por sociedades e organizações secretas a nível mundial, as quais consideram os seres humanos como um rebanho estúpido a ser dominado. O quarto círculo e seguintes misturam sociedades discretas e semi-secretas que captam os integrantes dos círculos inferiores, que configuram as elites e sub-elites econômicas, empresariais, militares, políticas, acadêmicas, culturais e religiosas que regem a economia e a sociedade. Os membros desses círculos, na sua imensa maior parte, ignoram a envergadura da estrutura à qual pertencem. Eles satisfazem sua cobiça, seu anseio por bens materiais, fama e reconhecimento social. Eles careceriam de escrúpulos e tudo seria válido para atingir seus objetivos.

O poder dessas elites se manteria devido à inconsciência das pessoas. Assim - e na linha de Marilyn Ferguson - a resistência contrária da conspiração consistiria basicamente em tornarse consciente. A consciência desencadearia uma elevação da "frequência vibratória" das pessoas, fazendo com que elas se voltem a uma dieta alimentícia sadia (veganismo), uma redução do estresse, que façam exercício e/ou meditação, ioga, tai-chi e considerem o próprio corpo como um templo sagrado. Isso tudo permitiria a elas descobrir o Ser Superior (CARRILLO, 2020, 255).

Carrillo considera que a humanidade e o mundo correm um gravíssimo perigo por causa dessa situação. Em mãos de cada pessoa individual estaria a responsabilidade de tornar-se consciente para cambiar o curso da história. E, de fato, ainda segundo Carrillo, na atualidade o mundo está mudando graças ao fato de existir um número significativo de seres humanos que vai conhecendo aos poucos a verdadeira natureza do inimigo. "Eles, sem querê-lo, estão acelerando nossa evolução coletiva... propiciando que nos unamos massivamente para construir um mundo melhor para todos" (CARRILLO, 2020, pp. 110-111, tradução nossa). No entanto, o ponto mais importante para superar a distopia estaria, segundo Carrillo, em amar a elite e a 
cada um de seus integrantes. Todos eles, do primeiro ao último, igual a cada um de nós, estaria no seu processo de evolução da consciência. Para eles a humanidade seria um "rebanho" destinado a ser dominado. Respondendo-lhes com ódio, se alimentaria num círculo de dualidade e confrontação. Amando-os se facilitaria que pudessem aumentar sua "frequência vibratória" e superar o círculo egoísta no qual eles se encontram presos (CARRILLO, 2020, p. 124).

\section{Reações à Conspiração Aquariana}

Marilyn Ferguson foi verdadeiramente uma sintetizadora do espírito da Nova Era. Denunciou as grandes conspirações que o grupo do movimento Nova Era reconhecia, apontou para os perigos que o planeta e a humanidade corriam devido a essas conspirações e, ao mesmo tempo, elaborou uma contra-conspiração aquariana, que supostamente levaria à tão almejada elevação espiritual.

A autora afirma em seu livro que, pelo fato de serem tão inovadoras, essas ideias produziriam resistência. E, de fato, no mesmo ano da publicação de A Conspiração Aquariana, a revista Executive Intelligence Review (EIR) ${ }^{5}$ publicou uma reportagem que, paradoxalmente, concordava com a ideia de conspiração aquariana de Ferguson. Só que em lugar de ser uma conspiração "para o bem" seria "para o mal". O livro de Ferguson seria, segundo essa publicação, uma fraude. No entanto, a publicação nada teria a objetar em relação à alegação conspirativa. Para os autores, a Conspiração Aquariana não teria sido um movimento espontâneo como afirmava Ferguson, mas promovido pelo Stanford Research Institute (SRI) ${ }^{6}$ como um programa de engenharia social encaminhado a uma lavagem cerebral massiva.

O primeiro exemplar da EIR que trata da Conspiração Aquariana é datado de maio 1980, portanto pouco depois da publicação do livro de Ferguson, em fevereiro do mesmo ano. O tema da Nova Era e da Conspiração Aquariana aparece em diversos números dessa revista ao longo dos anos, na mesma linha argumentativa.

Já em maio de 1980, Zoakos afirmava, neste número da EIR, que a população dos Estados Unidos estava sofrendo uma maciça lavagem cerebral por parte de um grande corpo de psicólogos sociais distribuídos em institutos de pesquisa, meios de comunicação e diversas agências governamentais e privadas. Os agentes dessa operação se referiam a si mesmos como

\footnotetext{
${ }^{5}$ Revista semanal de notícias e análise política fundada em 1974 pelo ativista político estadunidense Lyndon LaRouche.

${ }^{6}$ Instituto de pesquisa sem fins lucrativos sediado na California, EUA. 
a conspiradores aquarianos. O resultado estaria sendo uma crise moral, material, cultural e intelectual deliberadamente induzida. Segundo expressa Zoakos, projetos patrocinados pelo governo dos Estados Unidos ou financiados por instituições teriam "excretado detritos humanos" como ambientalistas, viciados em drogas, "malucos da yoga", meditadores transcendentais e "doidos dos biorritmos"9 (ZOAKOS, 1980, p. 21).

O livro de Marilyn Ferguson, prossegue Zoakos, estaria correto ao afirmar, segundo ele, que os grupos recém mencionados no parágrafo anterior, - junto aos Jesus freaks ${ }^{10}$, radicais de esquerda e de direita, libertários, grupos de consciência cósmica e outros - formariam parte de uma conspiração, só que, segundo ele, esta seria centralizada e coerente. No entanto, seria uma fraude no sentido de que teria plagiado um estudo interno do Stanford Research Institute (SRI) de maio 1974. O Dr. Willis Harman ${ }^{11}$, diretor de política social do SRI, teria solicitado a Ferguson para produzir uma versão popular desse estudo. Desse modo, o livro de Ferguson formaria parte de um programa massivo de engenharia social do SRI e outros. Assim, o programa passaria a ser público, ocultando, no entanto, os aspectos realmente importantes.

Zoakos termina afirmando que o establishment de psicologia social no seu todo está mobilizado para impor à sociedade a Conspiração Aquariana, Nova Era ou Era de Aquário ${ }^{12}$. Mediante uma série de programas de educação sexual, as crianças são instruídas, segundo ele, na masturbação, em "estilos de vida alternativos" - homossexualidade, lesbianismo, travestismo, prostituição "e assim por diante"; "cultos religiosos exóticos", como Hare Krishna ou Moonies; "movimentos carismáticos"; "teologia da libertação"; novo fundamentalismo religioso; shows televisivos, grupo Louva o Senhor (Praise the Lord); fundamentalismo islâmico; yoga; meditação transcendental; Ying-Yang; sufismo; excentricidades como biorritmos, telepatia, percepção extra-sensorial (ESP), telecinesia, astrologia; pessoas à procura de "experiências cósmicas" e "conscientização" mediante drogas - no momento em que os EUA atravessariam a pior epidemia de drogas da história. Esse alerta serviria para desmascarar os elementos constitutivos da Era de Aquário (ZOAKOS, 1980, p. 22).

Um estudo técnico do Stanford Research Institute, intitulado Imagens Cambiantes do Homem, teria como objetivo extirpar o senso interior de identidade do ser humano para

\footnotetext{
${ }^{7}$ No original, human refuse that has been excreted.

${ }^{8}$ No original, yoga-freak.

${ }^{9}$ No original biorhythm kook.

${ }^{10}$ Grupo cristão alemão caracterizado por efusão emocional.

${ }^{11}$ Em A Conspiração Aquariana, de Marily Ferguson, são citados regularmente o Stanford Research Institute e Willis Harman, seu diretor de pesquisa política.

12 No livro de Ferguson não aparece a expressão Nova Era, mas sim no artigo de Zoakos. REVISTA RELEGENS THRÉSKEIA - 2021 - UFPR
} 
substituí-lo por uma espúria alma sintética, artificial. Esse estudo teria sido popularizado no livro A Conspiração Aquariana. Figuras como B. F. Skinner e Margaret Mead participaram dessa obra. Nela, explica Zoakos, propõe-se alterar o comportamento da humanidade desde o industrialismo para o "espiritualismo" 13 , para o qual seria preciso primeiramente forçar uma mudança na autoimagem da humanidade (ZOAKOS, 1980, p. 22). Willis Harman, diretor de projeto do informe SRI, teria induzido Marilyn Ferguson a vangloriar-se de que se tratava de uma conspiração deliberada.

O fundamento estratégico da Conspiração Aquariana teria sido estabelecido pela OTAN $^{14}$, numa série de conferências nos anos 1966-1967. A intenção seria aplicar uma série de políticas em longo prazo para induzir uma transição a um "estado estacionário" tecnologicamente, ou "crescimento zero", ou "sociedade pós-industrial".

No mesmo número de EIR, Lyndon H. LaRouche Jr. vê na Conspiração Aquariana uma mistura de maniqueísmo, gnosticismo, os "magos da prostituta de Babilónia", os cultos a Dioniso, Isis, Apolo, os peripatéticos, o estoicismo, e "as religiões mistéricas romanas do César" (sic): nada novo, portanto, segundo ele. A lavagem cerebral anti-industrial, ambientalista, de drogas recreativas, orgias de dança rock, terrorismo, pornografia, homossexualidade e irracionalismo religioso carismático como o da "teologia da Libertação" jesuíta (sic), seriam tão antigos como o culto frígio a Dioniso. "A não ser que essa sodomia jesuíta-anglicana seja interrompida de imediato, aqui e agora, os Estados Unidos estarão condenados a morrer tão certo como Sodoma e Gomorra morreram a consequência da versão primeira desse programa jesuítico" (LAROUCHE, 1980, p. 35, tradução nossa).

Como explicação final, LaRouche expõe os fundamentos teológicos de sua visão. Tratar-se-ia de compreender a teologia apostólica cristã, por oposição aos cultos satânicos dos jesuítas e outros do tipo. O cristianismo salvou a humanidade da mesma coisa que os "jesuítas satânicos" (sic) propõem hoje como a Era de Aquário. Isto, segundo LaRouche, não seriam uma opinião senão um fato científico demonstrado empiricamente, "leis do universo que anglicanos, jesuítas e outros aquarianos satânicos estão insolentemente propondo violar hoje em dia" (LAROUCHE, 1980, p. 35, tradução nossa).

\section{Considerações finais}

\footnotetext{
${ }^{13}$ Entre aspas no original.

${ }^{14}$ Organização do Tratado do Atlântico Norte. 
Tal como advertia Ferguson, o seu livro A Conspiração Aquariana gerou fortes reações. Sem dúvida os artigos publicados na revista Executive Intelligence Review, poucos meses após a publicação do livro, é um bom exemplo. As acusações da EIR a Ferguson, entram também plenamente na lógica do conspiracionismo, a ponto de reinterpretar a conspiração aquariana como obra de uma minoria malévola com a intenção de destruir a sociedade e os valores que a sustentam. Essa acusação se apoia em argumentos explicitamente religiosos, com suas alusões a antigas heresias contrapostas ao que eles entendem como teologia apostólica cristã. Essa teologia teria, segundo afirmam, uma justificativa rigorosamente científica. É interessante o paralelo com a fundamentação ocultista da Nova Era, pela qual os fenômenos religiosos "corretos" também teriam uma explicação científica.

Religiões e teorias da conspiração compartem representações e mecanismos cognitivos. Por esse motivo as teorias da conspiração se encontram presentes na Nova Era. A Nova Era apresenta características relacionadas ao gnosticismo, no sentido de uma visão do mundo dividido entre bem e mal e acesso a uma sabedoria oculta que libertaria desse mal. Na medida em que o conspiracionismo é um mecanismo cognitivo espontâneo do ser humano, gera ao redor da Nova Era uma dialética de enxergar conspirações em lados opostos: seja contra um conhecimento interior ou gnose libertadora, ou "do bem", e de um outro lado, como subversão de valores em que se alicerça a sociedade.

Mesmo atualmente, passadas décadas do movimento de contracultura e da emergência do Movimento da Era de Aquário, o ethos nova era gera as condições propícias para o surgimento e a manutenção de novas teorias da conspiração. Coerente à diversidade implícita dessa religiosidade difusa, o posicionamento político de cada uma das teorias conspiratórias, concordando com interesses momentâneos e localizados, pode soprar de acordo com o vento.

\section{REFERÊNCIAS}

CAMPBELL, Colin. The Cult, the cultic milieu, and secularization. In: HILL M. (ed.). A Sociological yearbook of Religion in Britain, London: SCM Press, 1972. p. 119-136. A orientalização do Ocidente: reflexões sobre uma nova teodicéia para um novo milênio. Religião e Sociedade, 18, 1, p. 5-22, 1997.

CARRILLO, Emilio et. al. Consciencia y sociedad distópica. Coronavirus: un estudio de caso. Sevilla: Adaliz Ediciones, 2020.

DURÁN, Astrid M. P.; LOPEZ MOYA, Martín de la C. Extraterrestres en el imaginario del New Age: redes de espiritualidad y utopía desde San Cristóbal de Las Casas, Chiapas. LiminaR (online), vol. 9, p. 63-82, 2011. Disponível em 
$<$ http://www.scielo.org.mx/scielo.php?script=sci_arttext\&pid=S1665$80272011000200005 \& \operatorname{lng}=e s \& n r m=i s o>$. Acesso em 02 dez. 2021.

FERGUSON, Marilyn. A conspiração aquariana. Transformações pessoais e sociais nos anos 80. Rio de Janeiro: Record, 1995.

FRANKS, B.; BANGERTER, A; BAUER, M. Conspiracy theories as quasi-religious mentality: an integrated account from cognitive science, social representations theory, and frame theory. Frontiers in Psychology, 4, p. 1-12, jul 2013.

GOODRICK-CLARKE, Nicholas. Black Sun. Aryan Cults, Esoteric Nazism and the Politics of Identity. New York and London: New York University Press, 2002.

GUERRIERO, Silas, et al. Os componentes constitutivos da Nova Era: a formação de um novo ethos. Rever, 16, 2, p.10-30, 2016.

GUERRIERO, Silas. Fundamentalismos na Nova Era: violência e intolerância a partir da noção de divindade. In: PACE, Enzo; OLIVEIRA, Irene D.; AUBRÉE, Marion (Orgs). Fundamentalismos religiosos, violência e sociedade. São Paulo: Fonte Editorial; Edições Terceira Via, 2017. p. 93-110.

GUERRIERO, Silas. Intolerância e relativismo: o dinamismo das novas religiões no Brasil. Estudos de religião, Estudos de Religião, Ano XIX, nº 29, p. 37-55, jul/dez 2005.

HANEGRAAFF, Wouter. New Age religion and western culture, esotericism in the mirror of secular thought. Leiden: Brill Academic Publishers. 1996.

HANEGRAAFF, Wouter J. Romanticism and the Esoteric Connection. In: BROEK, R.; HANEGRAAFF, W. J. (eds.). Gnosis and Hermeticism. From antiquity to modern times. New York: State University of New York Press, 1998.

LAROUCHE Jr. Lyndon. The difference between their Science and ours. Executive Intelligence Review (EIR), volume 7, number 18, May 1980. Disponível em <https://larouchepub.com/eiw/public/1980/eirv07n18-19800513/index.html>. Acesso em: 04 ago. 2021.

LISBOA, Daniel. Grupo que acredita em "volta dos ET's à Terra" quer embaixada no Brasil. Metrópoles, 2021. Disponível em: <https://www.metropoles.com/brasil/grupo-que-acreditaem-volta-dos-ets-a-terra-quer-embaixada-no-brasil>. Acesso em: 25 jul. 2021.

MACHADO, Carly Barbosa. Imagine se tudo isso for verdade: O movimento Raeliano entre verdades, ficções e religiões na modernidade. Rio de Janeiro: UERJ, 2006 (Doutorado em Ciências Sociais).

SPANGLER, David. Apprenticed to Spirit. The education of a soul. New York: Riverhead Books, 2010.

VERONESI, Michele. Deuses vindos do espaço: a crença religiosa em extraterrestres. Revista Nures, ano VIII, n² 21, p. 1-12, set-dez 2012. 
ZOAKOS, Criton. Tavistock: 'mother' of panned madness. Executive Intelligence Review (EIR), volume 7, number 18, May 1980. Disponível em: https://larouchepub.com/eiw/public/1980/eirv07n18-19800513/index.html. Acesso em 04 ago. 2021.

ZOAKOS, Criton. The Aquarian Conspiracy's Road to Orwell's 1984. Executive Intelligence Review (EIR), volume 7, number 18, May 13, 1980. Disponível em: https://larouchepub.com/eiw/public/1980/eirv07n18-19800513/index.html. Acesso em 04 ago. 2021. 